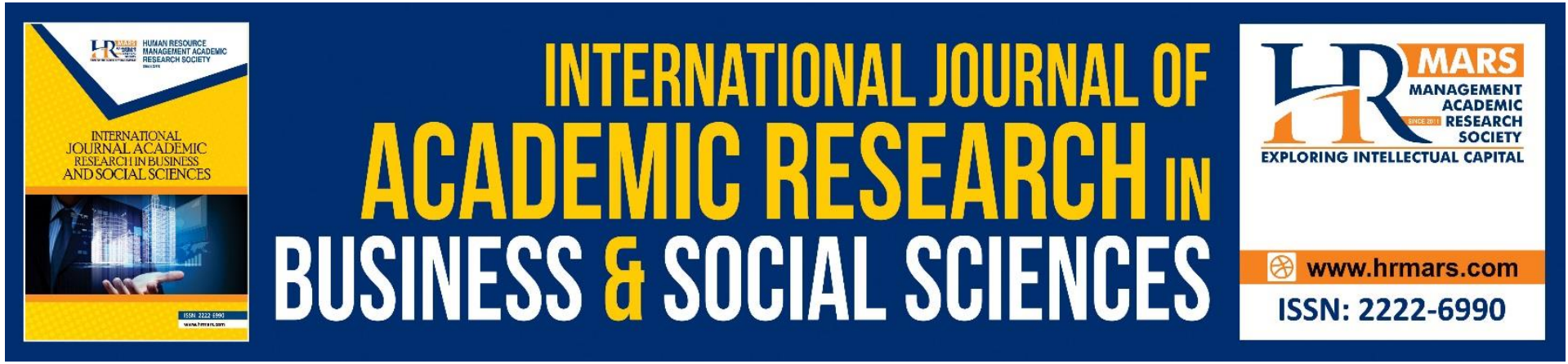

\title{
Design and Optimization of Piezoelectric Cantilever for Energy Harvesting Application by Using Taguchi Method
}

\section{Muhammad Haziq Bin Ismail, Yusnira Husaini}

To Link this Article: http://dx.doi.org/10.6007/IJARBSS/v11-i9/10342

Received: 02 July 2021, Revised: 27 July 2021, Accepted: 20 August 2021

Published Online: 07 September 2021

In-Text Citation: (Ismail \& Husaini, 2021)

To Cite this Article: Ismail, M. H. Bin, \& Husaini, Y. (2021). Design and Optimization of Piezoelectric Cantilever for Energy Harvesting Application by Using Taguchi Method. International Journal of Academic Research in Business and Social Sciences, 11(9), 162-172.

Copyright: @ 2021 The Author(s)

Published by Human Resource Management Academic Research Society (www.hrmars.com) This article is published under the Creative Commons Attribution (CC BY 4.0) license. Anyone may reproduce, distribute, translate and create derivative works of this article (for both commercial and non-commercial purposes), subject to full attribution to the original publication and authors. The full terms of this license may be seen at: http://creativecommons.org/licences/by/4.0/legalcode

Vol. 11, No. 9, 2021, Pg. 162 - 172

Full Terms \& Conditions of access and use can be found at http://hrmars.com/index.php/pages/detail/publication-ethics 


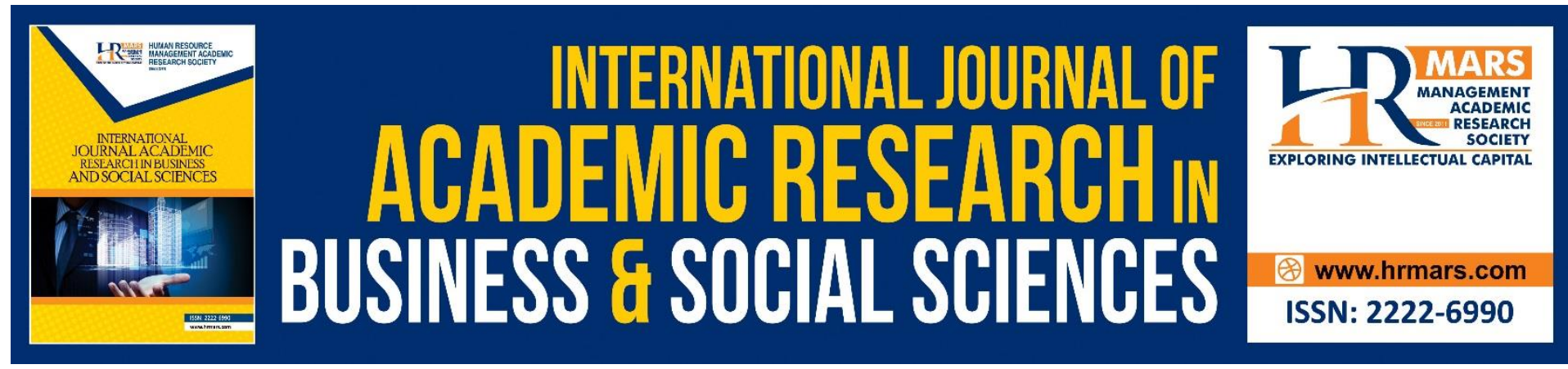

\title{
Design and Optimization of Piezoelectric Cantilever for Energy Harvesting Application by Using Taguchi Method
}

\author{
Muhammad Haziq Bin Ismail, Yusnira Husaini \\ Integrated Microelectronic System and Applications (IMSaA), Kolej Pengajian Kejuruteraan, \\ Universiti Teknologi MARA Shah Alam, Selangor, Malaysia \\ Email: yusni458@uitm.edu.my
}

\begin{abstract}
Piezoelectric element is one of the best innovation and technologies to be utilized in energy harvesting to produce electrical energy from vibrations. It can give a perfect and independent arrangement solution that can be stored and used to power some wireless sensors, electronic device, and other low-power applications. With this goal in mind, a design and optimization of piezoelectric cantilever beam for energy harvesting has been developed. The focus of this paper is to discuss the design and optimization of piezoelectric cantilever beam by using Taguchi method for determine the optimal design parameters. For this study, the design of the bimorph piezoelectric harvester was performed by COMSOL software. Three parameters which are load resistance, width and length of piezoelectric cantilever has been considered. The parameters were optimized by using L16 orthogonal array Taguchi method. Optimization results showed that load resistance, width and length were found to be $10 \mathrm{k} \Omega, 17 \mathrm{~mm}$, and $23 \mathrm{~mm}$ respectively. The optimized outputs are $1.78 \mathrm{~mW}$ electrical power at $5.97 \mathrm{~V}$ for resonant frequency of $65 \mathrm{~Hz}$.
\end{abstract}

Keywords: Piezoelectric, Energy Harvester, Cantilever, Taguchi Method, COMSOL

\section{Introduction}

Energy harvesting (EH) or energy scavenging is a process of capturing small amount of energy from ambient environment through various sources of energy. Engineers are challenged to design state-of-the-art systems which beneficial to humankind and power themselves from available ambient energy. Harvesters can be used as battery rechargers in various places, such as industries, houses and wearable devices (Torah et al., 2008). To date, energy harvesting have drawn great attention for wireless sensor networks power to solve a series of problems such as short life span, size and pollution. Piezoelectric devices have proven to be a potential source of power generation (Marusiak, 2012).

There are three main components in piezoelectric ambient vibration energy harvesting system as shown in Figure 1 . The three main components are rectifier, voltage regulator, and energy storage device. Rectifier is used to convert alternating current (AC) to direct current (DC). Full wave bridge rectifiers is the most frequently used AC-DC rectifier for the energy 
harvesting systems (Al-Ashtari, 2013; Kalyanaraman \& Babu, 2010; Sodano et al., 2005a). Next, the voltage regulator is used to regulate voltage levels that produced from the piezoelectric element. Since piezoelectric energy harvester yield low power output, it is not sufficient to power up the electronic devices. Hence, in the piezoelectric energy harvesting system, the harvested energy is usually first collected in a storage medium before being used by the load. The energy storage that commanly used are rechargeable batteries and capacitor (Shad Roundy et al., 2003; Sodano et al., 2005b; Zhang et al., 2016).

In energy harvesting, Han et al. investigated on synchronous rectifier and compared the performance with other existing rectifiers (Han et al., 2004). From their study, the circuit operated through two stages which are AC-DC rectifier and DC-DC converter. From their analysis, the most efficient method was synchronous rectification based on the three different rectifier circuits using simulation.

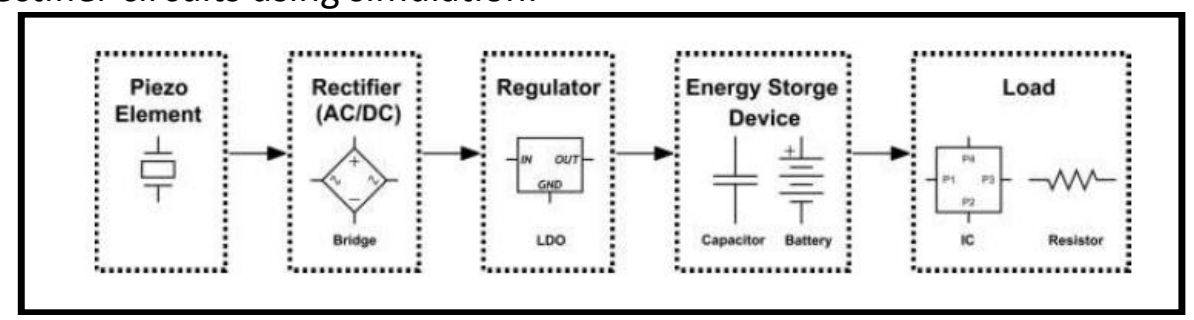

Figure 1 Block diagram of piezoelectric ambient vibration energy harvesting system

The performance of the energy harvester can be affected by different piezoelectric materials due to different piezoelectric constants. Some examples of piezoelectric materials are zinc oxide ( $\mathrm{ZnO})$, aluminum nitrate (AIN), lead zirconate titanate (PZT) and polyvinylidene fluoride (PVDF). Among the piezoelectric materials, PZT is the most commonly used piezoelectric material because has higher piezoelectric coefficient and high dielectric constant (Kuoni et al., 2003). According to Roundy's paper, the study focuses on modeling, design, and optimization of a piezoelectric energy harvester based on the bimorph cantilever. The cantilever was made using PZT material. Roundy observed that the design of the energy harvester must target low frequency fundamental mode compared to the higher frequency mode. This is because the potential output power is proportional to $1 / \omega$ where $\omega$ is the frequency of the fundamental vibration mode (S. Roundy \& Wright, 2004). The purpose of this paper is to research and design piezoelectric for low power device application, to run modeling and simulation of MEMS piezoelectric energy harvester using COMSOL tool and to optimize the design of piezoelectric circuit by Taguchi Method Orthogonal Array.

\section{A. The piezoelectric cantilever configuration}

When pressure is applied to piezoelectric materials, an electric voltage develops across the material. The two constitutive equations can model mechanical and electrical behavior ( $\mathrm{S}$. Roundy \& Wright, 2004):

$$
\begin{aligned}
& S=s^{E} T+d_{t} E \\
& D=d_{t} T+\varepsilon^{T} E
\end{aligned}
$$

where $S$ - mechanical strain, $T$ - applied mechanical stress, E - Electric field, D - electric displacement, $s^{E}$ - matrix of elasticity under conditions of constant electric field, d piezoelectric coefficient matrix, and $\varepsilon^{T}$ - permittivity matrix at constant mechanical strain. Large deformation can be produced by the simple structure of cantilever type energy harvesting. There are two different mode that can be used in this model of cantilever. Firstly, the 33 mode called compressive mode in which the voltage is recoverd in the three direction parallel to the direction of applied force. The other is 31 mode called transverse mode where 
the voltage is recovered in one direction perpendicular to the direction of applied force. The most useful mode in harvesting applications is 31 mode because an immense proof mass would be needed for the 33 mode configuration (Lefeuvre et al., 2007).

B. Taguchi Method Orthogonal Array

One of the most comprehensive approach in product or process developments is consider design of experiments (DOE). It is a statistical approach that attempts to provide a predictive knowledge of a complex, multi-variable process with few trials (Rafidah et al., 2014). One of statistical approach is Taguchi method that can optimize the process parameters and improve the quality of components that are manufactured. Taguchi method was used to construct set of arrays called orthogonal arrays, which advocate minimum number of experiments with maximum information about all the factors that affect the outcome (Athreya \& Venkatesh, 2012).

\section{Methodology}

A. Design of piezoelectric harvester

The model is designed in COMSOL software. A two dimension bimorph cantilever was consisted of two material. Lead zirconate titanate (PZT-5A) material is used as piezoelectric layer (top and bottom) and structural steel is used as substrate (middle).The energy harvester considered for the study is in the form of the cantilever shown in Figure 2 . It consists of a piezoelectric bimorph with a proof mass mounted on the other end. The bimorph is grounded by embedded within it and two electrode on the exterior surface of the cantilever beam. The cantilever's dimension is $21 \mathrm{~mm}$ length, $14 \mathrm{~mm}$ width and $4 \mathrm{~mm} \mathrm{x}$ $1.7 \mathrm{~mm}$ proof mass as shown in Table 1 (Desai et al., 2016).

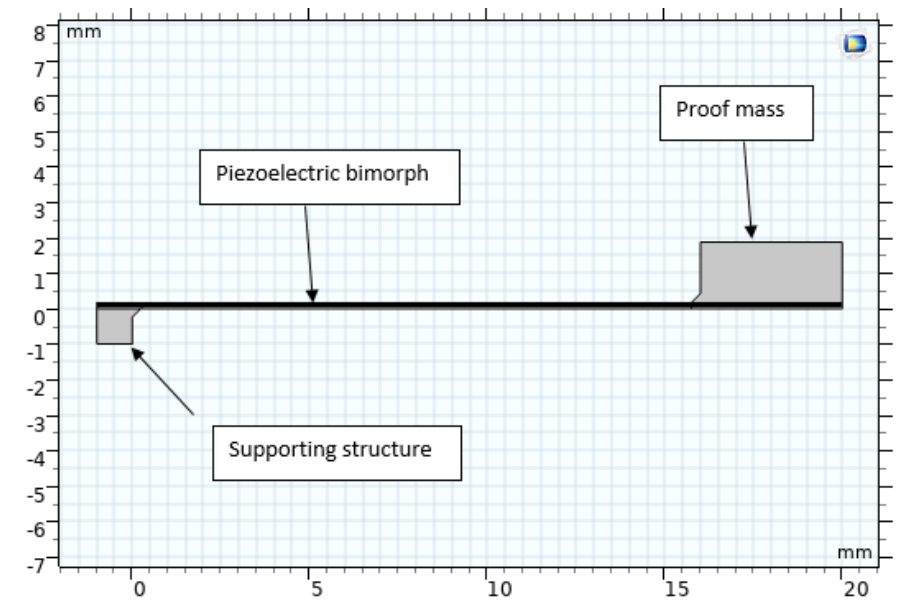

Figure 2 Configuration of bimorph piezoelectric cantilever in COMSOL

Table 1 Initial values of the input parameters

\begin{tabular}{l|l}
\hline Load resistance & $12 \mathrm{k} \Omega$ \\
\hline Width of piezo plate & $14 \mathrm{~mm}$ \\
\hline Length of piezo plate & $21 \mathrm{~mm}$ \\
\hline Proof mass dimensions & $4 \mathrm{~mm} \times 1.7 \mathrm{~mm}$ \\
\hline
\end{tabular}

\section{B. Experimental design using the Taguchi method}

In this study, it is considering three parameters which are load resistance, width, and length of piezo plate, with four levels for each parameter. The studied factors of the three 
parameters and four levels are given in Table 2. In full factorial experiments, 64 experiments must be performed. By using an orthogonal array suggested by Taguchi, the number of experiments needed to find the optimal parameters will be significantly reduced. Concerning the proposed parameters and levels, an L16 orthogonal array experiment was considered as shown in Table 3.

Table 2 Levels of input parameters

\begin{tabular}{lllll}
\hline Parameters & \multicolumn{3}{l}{ Levels } \\
\cline { 2 - 5 } & $\mathbf{1}$ & $\mathbf{2}$ & $\mathbf{3}$ & $\mathbf{4}$ \\
\hline Load resistance $(\mathbf{k} \boldsymbol{\Omega})$ & 10 & 12 & 14 & 16 \\
\hline Width of piezo plate $(\mathbf{m m})$ & 11 & 13 & 15 & 17 \\
\hline Length of piezo plate $(\mathbf{m m})$ & 20 & 21 & 22 & 23 \\
\hline
\end{tabular}

Table 3 The L16 Orthogonal Array Experiment

\begin{tabular}{llll}
\hline Experiment No. & $\begin{array}{l}\text { Load } \\
\text { Level }\end{array}$ & Width & Length \\
\hline $\mathbf{1}$ & 1 & 1 & 1 \\
$\mathbf{2}$ & 1 & 2 & 2 \\
$\mathbf{3}$ & 1 & 3 & 3 \\
$\mathbf{4}$ & 1 & 4 & 4 \\
$\mathbf{5}$ & 2 & 1 & 2 \\
$\mathbf{6}$ & 2 & 2 & 1 \\
$\mathbf{7}$ & 2 & 3 & 4 \\
$\mathbf{8}$ & 2 & 4 & 3 \\
$\mathbf{9}$ & 3 & 1 & 3 \\
$\mathbf{1 0}$ & 3 & 2 & 4 \\
$\mathbf{1 1}$ & 3 & 3 & 1 \\
$\mathbf{1 2}$ & 3 & 4 & 2 \\
$\mathbf{1 3}$ & 4 & 1 & 4 \\
$\mathbf{1 4}$ & 4 & 2 & 3 \\
$\mathbf{1 5}$ & 4 & 3 & 2 \\
$\mathbf{1 6}$ & 4 & 4 & 1 \\
\hline
\end{tabular}

\section{Results and Discussion}

Taguchi method was used to construct a systematic approach to screen for the most sensitive input parameters that will effect the piezoelectric output parameters. Table 4 shows the effect of input parameters to the output parameters, namely the resonant frequency, voltage and electrical power. The input parameters studied are load resistance, width of piezo plate, and length of piezo plate. Figure 3 shows a sample of simulated output results for experiment run number 1 in Taguchi Orthogonal Array (Table 4). 
Table 4 Taguchi Orthogonal Array showing the variation of output parameters with optimum combinations of input parameters

\begin{tabular}{|c|c|c|c|c|c|c|}
\hline $\begin{array}{l}\text { Exp. } \\
\text { Run }\end{array}$ & $\begin{array}{l}\text { Load } \\
(\mathrm{k} \Omega)\end{array}$ & $\begin{array}{l}\text { Width } \\
\text { of } \\
\text { piezo } \\
\text { plate } \\
(\mathrm{mm})\end{array}$ & $\begin{array}{l}\text { Length } \\
\text { of } \\
\text { piezo } \\
\text { plate } \\
(\mathrm{mm}) \\
\end{array}$ & $\begin{array}{l}\text { Resonant } \\
\text { Frequency } \\
\text { (Hz) }\end{array}$ & $\begin{array}{l}\text { Voltage } \\
\text { (V) }\end{array}$ & $\begin{array}{l}\text { Electrical } \\
\text { Power } \\
\text { (mW) }\end{array}$ \\
\hline 1 & 10 & 11 & 20 & 82.5 & 4.67 & 1.09 \\
\hline 2 & 10 & 13 & 21 & 76 & 5.07 & 1.28 \\
\hline 3 & 10 & 15 & 22 & 70 & 5.52 & 1.52 \\
\hline 4 & 10 & 17 & 23 & 65 & 5.97 & 1.78 \\
\hline 5 & 12 & 11 & 21 & 76 & 5.09 & 1.08 \\
\hline 6 & 12 & 13 & 20 & 83 & 4.99 & 1.04 \\
\hline 7 & 12 & 15 & 23 & 65 & 6.06 & 1.53 \\
\hline 8 & 12 & 17 & 22 & 71 & 5.97 & 1.48 \\
\hline 9 & 14 & 11 & 22 & 70 & 5.55 & 1.10 \\
\hline 10 & 14 & 13 & 23 & 65 & 6.07 & 1.32 \\
\hline 11 & 14 & 15 & 20 & 84 & 5.46 & 1.06 \\
\hline 12 & 14 & 17 & 21 & 77.5 & 6.03 & 1.30 \\
\hline 13 & 16 & 11 & 23 & 65 & 6.02 & 1.13 \\
\hline 14 & 16 & 13 & 22 & 71 & 6.02 & 1.13 \\
\hline 15 & 16 & 15 & 21 & 77.5 & 6.06 & 1.14 \\
\hline 16 & 16 & 17 & 20 & 85 & 6.12 & 1.17 \\
\hline
\end{tabular}

Table 5 Respond table for means resonant frequency with respect to parameters set.

\begin{tabular}{llll}
\hline Level & $\begin{array}{l}\text { Load } \\
\text { Resistance } \\
\text { (k } \mathbf{)}\end{array}$ & $\begin{array}{l}\text { Width } \\
(\mathbf{m m})\end{array}$ & $\begin{array}{l}\text { Length } \\
(\mathbf{m m})\end{array}$ \\
\hline 1 & 73.38 & 73.38 & 83.63 \\
2 & 73.75 & 73.75 & 76.75 \\
3 & 74.13 & 74.13 & 70.50 \\
4 & 74.63 & 74.63 & 65.00 \\
Delta & 1.25 & 1.25 & 18.63 \\
Rank & 2.5 & 2.5 & 1 \\
\hline
\end{tabular}

From Table 4, it has been seen that the voltage and electrical power increase when the length and width of piezo plate increase for experiment run 1 to 4 . However, the shift of resonant frequency has also changed for those experiments. Next, based on the experiments run, analysis on resonant frequency, voltage and electrical power are being analyzed as in Table 5, Table 6, and Table 7 respectively. The main effect plots are the mean response of each level factors connected by the line. When the horizontal line presents, there is no main effect present. As small deflection from horizontal, it may significantly affect the response. Steeper slope in the line illustrates the greater magnitude of the main effect. 


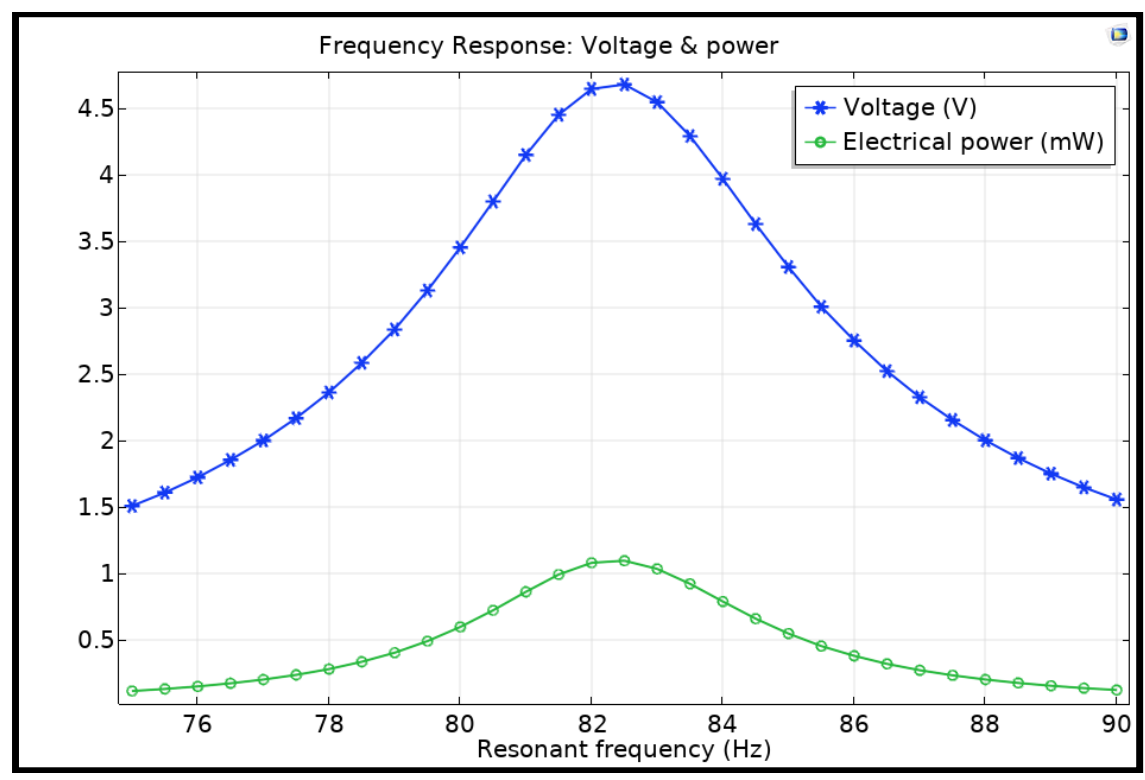

Figure 3 Simulation result for experiment run 1 using COMSOL tool.

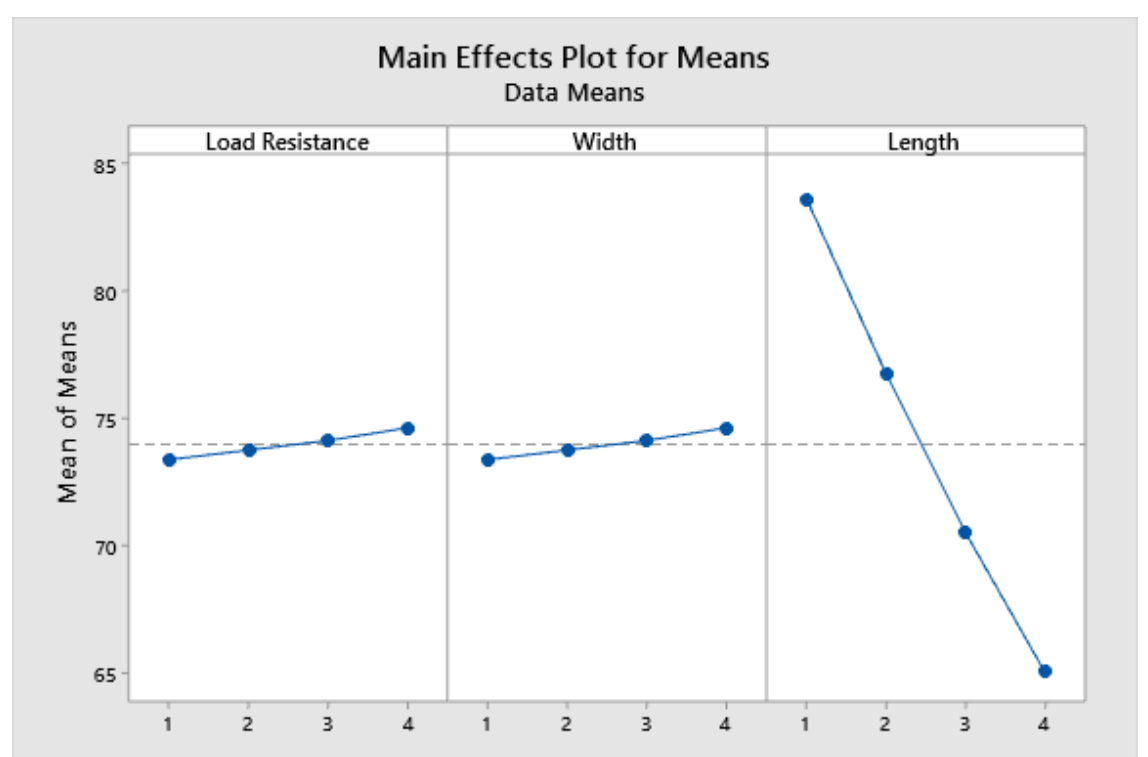

Figure 4 Graph of main effects plot for means resonant frequency versus load, width, and length

The means of resonant frequency with load, width and length of the plate are shown in Figure 4. The length of the plate has great impact on the frequency of the cantilever. The resonant frequency decreased as the length increased. The load resistance and width of the plate has least significant effect on the resonant frequency. It is concluded that the frequency is inversely proportional to the length of piezo plate. 
Table 6 Respond table for means voltage with respect to parameters set.

\begin{tabular}{llll}
\hline Level & $\begin{array}{l}\text { Load } \\
\text { Resistance } \\
(\mathbf{k} \Omega)\end{array}$ & $\begin{array}{l}\text { Width } \\
(\mathbf{m m})\end{array}$ & $\begin{array}{l}\text { Length } \\
(\mathbf{m m})\end{array}$ \\
\hline 1 & 5.308 & 5.332 & 5.310 \\
2 & 5.527 & 5.538 & 5.563 \\
3 & 5.778 & 5.775 & 5.765 \\
4 & 6.055 & 6.022 & 6.030 \\
Delta & 0.747 & 0.690 & 0.720 \\
Rank & 1 & 3 & 2 \\
\hline
\end{tabular}

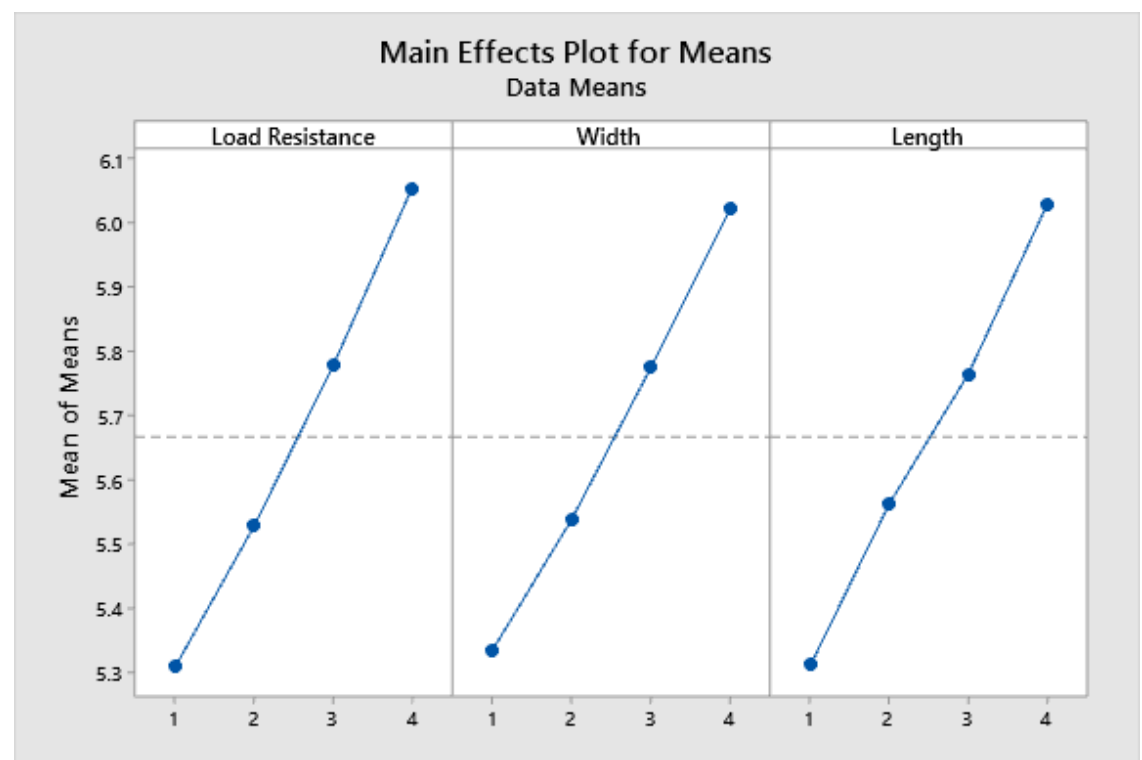

Figure 5 Graph of main effects plot for means voltage versus load, width, and length

The means of voltage with load, width and length of the plate are shown in Figure 5 . The three parameters have high sensitivity on the voltage of the cantilever. Therefore, the voltage is directly proportional to the load, width, and length of piezo plate.

Table 7 Respond table for means electrical power with respect to parameters set.

\begin{tabular}{llll}
\hline Level & $\begin{array}{l}\text { Load } \\
\text { Resistance } \\
\text { (k } \boldsymbol{\Omega})\end{array}$ & $\begin{array}{l}\text { Width } \\
(\mathbf{m m})\end{array}$ & $\begin{array}{l}\text { Length } \\
(\mathbf{m m})\end{array}$ \\
\hline 1 & 1.417 & 1.100 & 1.090 \\
2 & 1.283 & 1.193 & 1.200 \\
3 & 1.195 & 1.312 & 1.307 \\
4 & 1.142 & 1.432 & 1.440 \\
Delta & 0.275 & 0.332 & 0.350 \\
Rank & 3 & 2 & 1 \\
\hline
\end{tabular}




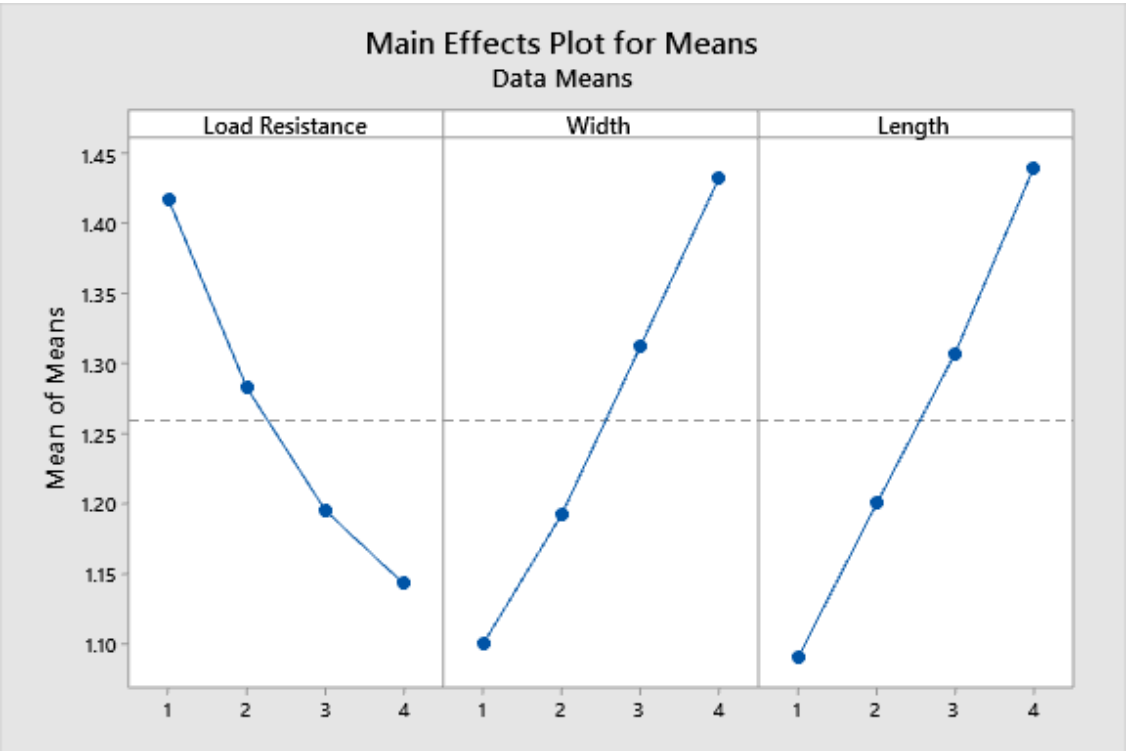

Figure 6 Graph of main effects plot for means electrical power versus load, width, and length

The means of electrical power with load, width, and length are shown in Figure 6 . The electrical power has decreased as the load resistance increased. Meanwhile, the increase of width and length have increased the electrical power. Based on the analysis, load resistance of 1.417, level 4 of width and level 4 of length were selected for the optimal design of the piezoelectric energy harvester to get high voltage and electric power at a low scale resonant frequency. The optimal value for load resistance, width and length were found to be $10 \mathrm{k} \Omega$, $17 \mathrm{~mm}$, and $23 \mathrm{~mm}$ respectively. From Table 4, it can be observed that the electrical power is maximum value of $1.78 \mathrm{~mW}$ when the voltage is $5.97 \mathrm{~V}$ at a low scale resonant frequency which is $65 \mathrm{~Hz}$.

\section{Conclusion}

In conclusion, energy harvesting from bimorph piezoelectric cantilever beam was studied successfully. Taguchi method was used to optimize the parameter of the energy harvester. An L16 orthogonal array was considered, and simulation of each experiment was run using COMSOL software. It is found that Taguchi method provides cost effectiveness as it reduces the number of experiments in studying the sensitivity effect of the design parameters. In this study, the resonant frequency is inversely proportional to the length of piezo plate. From the results, it was found out that bimorph piezoelectric energy harvester with load resistance of $10 \mathrm{k} \Omega$, width of $17 \mathrm{~mm}$ and length of $23 \mathrm{~mm}$ generated $5.97 \mathrm{~V}$ electric potential and $1.78 \mathrm{~mW}$ electrical power under the resonance frequency of $65 \mathrm{~Hz}$. Despite the energy that harvested from the cantilever is small and in the range of milliwatts, the power was capable to bias some wireless sensors, electronic device, and other low-power applications. For future work on investigating the optimization of unimorph devices is recommended. Therefore, significant differences can be found in the trends between performance and geometric parameters especially when studying the effects of layer thickness, width and length of the piezoelectric.

\section{Acknowledgment}

Authors would like to thank ReNeU, UiTM for sponsoring this publication. 


\section{References}

Al-Ashtari, W. (2013). Characteristics of Piezoelectric Energy Harvesters in Autonomous Systems. IWPMA \& EHW,14.-18.07.2013 : 10th International Workshop of Piezoelectric Materials and Applications in Actuators, 8th Annual Energy Harvesting Workshop, July, 1-3. https://doi.org/10.2314/IWPMA_01

Athreya, S., \& Venkatesh, Y. D. (2012). Application Of Taguchi Method For Optimization Of Process Parameters In Improving The Surface Roughness Of Lathe Facing Operation. International Refereed Journal of Engineering and Science, 1(3), 13-19. https://doi.org/2319-1821

Desai, T., Dudhe, R., \& Ayyalusamy, S. (2016). Design, Simulation and Optimization of Bimorph Piezoelectric Energy Harvester. 1-4.

Han, J., Von Jouanne, A., Le, T., Mayaram, K., \& Fiez, T. S. (2004). Novel power conditioning circuits for piezoelectric micro power generators. Conference Proceedings - IEEE Applied Power Electronics Conference and Exposition - APEC. https://doi.org/10.1109/apec.2004.1296069

Kalyanaraman, K., \& Babu, J. (2010). Power Harvesting System in Mobile Phones and Laptops using Piezoelectric Charge Generation. Lecture Notes in Engineering and Computer Science, 2187(1), 879-882.

Kuoni, A., Holzherr, R., Boillat, M., \& De Rooij, N. F. (2003). Polyimide membrane with ZnO piezoelectric thin film pressure transducers as a differential pressure liquid flow sensor. Journal of Micromechanics and Microengineering. https://doi.org/10.1088/0960$1317 / 13 / 4 / 317$

Lefeuvre, E., Audigier, D., Richard, C., \& Guyomar, D. (2007). Buck-boost converter for sensorless power optimization of piezoelectric energy harvester. IEEE Transactions on Power Electronics, 22(5), 2018-2025. https://doi.org/10.1109/TPEL.2007.904230

Marusiak, D. (2012). Design and Simulation of Unimorph Piezoelectric Energy Harvesting System. Electronic Components \& Technology Conference, June, 2018-2023.

Rafidah, A., Nurulhuda, A., Azrina, A., Suhaila, Y., Anwar, I. S., \& Syafiq, R. A. (2014). Comparison design of experiment (DOE): Taguchi method and full factorial design in surface roughness. Applied Mechanics and Materials.

https://doi.org/10.4028/www.scientific.net/AMM.660.275

Roundy, S., \& Wright, P. K. (2004). A piezoelectric vibration based generator for wireless electronics. Smart Materials and Structures, 13(5), 1131-1142.

https://doi.org/10.1088/0964-1726/13/5/018

Roundy, Shad, Wright, P. K., \& Rabaey, J. (2003). A study of low level vibrations as a power source for wireless sensor nodes. 26, 1131-1144.

Sodano, H. A., Inman, D. J., \& Park, G. (2005a). Comparison of piezoelectric energy harvesting devices for recharging batteries. Journal of Intelligent Material Systems and Structures, 16(10), 799-807. https://doi.org/10.1177/1045389X05056681

Sodano, H. A., Inman, D. J., \& Park, G. (2005b). Generation and storage of electricity from power harvesting devices. Journal of Intelligent Material Systems and Structures, 16(1), 67-75. https://doi.org/10.1177/1045389X05047210

Torah, R., Glynne-Jones, P., Tudor, M., O’Donnell, T., Roy, S., \& Beeby, S. (2008). Self-powered autonomous wireless sensor node using vibration energy harvesting. Measurement Science and Technology, 19(12). https://doi.org/10.1088/0957-0233/19/12/125202

Zhang, G., Gao, S., \& Liu, H. (2016). A utility piezoelectric energy harvester with low frequency and high-output voltage: Theoretical model, experimental verification and energy 
INTERNATIONAL JOURNAL OF ACADEMIC RESEARCH IN BUSINESS AND SOCIAL SCIENCES Vol. 11, No. 9, 2021, E-ISSN: 2222-6990 @ 2021 HRMARS

storage. AIP Advances, 6(9). https://doi.org/10.1063/1.4962979 